\title{
The dynamics of rapidly emplaced terrestrial lava flows and implications for planetary volcanism
}

\author{
Stephen Baloga \\ Proxemy Research, Inc., Laytonsville, Maryland \\ NASA Goddard Space Flight Center, Greenbelt, Maryland \\ Paul D. Spudis \\ Lunar and Planctary Institute, Houston, Texas \\ John E. Guest \\ University of London Observatory, London, England
}

\begin{abstract}
The Kaupulehu 1800-1801 lava flow of Hualalai volcano and the 1823 Keaiwa flow from the Great Crack of the Kilauea southwest rift zone had certain unusual and possibly unique properties for terrestrial basaltic lava flows. Both flows apparently had very low viscosities, high effusion rates, and uncommonly rapid rates of advance. Ultramafic xenolith nodules in the 1801 flow form stacks of cobbles with lava rinds of only millimeter thicknesses. The velocity of the lava stream in the 1801 flow was extremely high, at least $10 \mathrm{~m} \mathrm{~s}^{-1}$ (more than $40 \mathrm{~km} \mathrm{~h}^{-1}$ ). Observations and geological evidence suggest similarly high velocities for the 1823 flow. The unusual eruption conditions that produced these lava flows suggest a floodlike mode of emplacement unlike that of most other present-day flows. Although considerable effort has gone into understanding the viscous fluid dynamics and thermal processes that often occur in basaltic flows, the unusual conditions prevalent for the Kaupulehu and Keaiwa flows necessitate different modeling considerations. We propose an elementary flood model for this type of lava emplacement and show that it produces consistent agreement with the overall dimensions of the flow, channel sizes, and other supporting field evidence. The reconstructed dynamics of these rapidly emplaced terrestrial lava flows provide significant insights about the nature of these eruptions and their analogs in planetary volcanism.
\end{abstract}

\section{Introduction}

The 1800-1801 eruption of the Hualalai volcano and the 1823 eruption of Kilauea volcano provide unique opportunities for investigating the dynamics of rapidly emplaced lava flows. These eruptions featured unusually high rates of discharge combined with relatively low lava viscosities, conditions thought to be present in certain planetary settings. The overall dimensions, planimetric forms, and general morphologic characteristics of these Hawaiian flows seem to suggest physical processes of emplacement that are usually considered commonplace in basaltic volcanism, for example, laminar viscous fluid flow, cooling by radiation, incipient crystallization, and the formation of an insulating surficial crust. However, it has long been known that these flows are relatively unusual among terrestrial basaltic eruptions [e.g., Steams, 1926; Richter and Murata, 1961] in featuring such high volumetric rates of effusion and low magma viscosities.

More than 50 years ago, Nichols [1939] correctly pointed out that sufficiently slow-moving lava flows should be treated quantitatively by laminar viscous fluid dynamics, rather than a semiempirical formalism for turbulent water flow. Nichols also noted, in effect, the defining condition for a sufficiently slowmoving laminar flow, namely, that the movement of any fila-

Copyright 1995 by the American Geophysical Union.

Paper number 95JB(2844.

$0148-(0227 / 95 / 95 \mathrm{JB}-(2844 \$ 1) 5.00$ ment within the flow is locally parallel to all other filaments. With noteworthy insight, Nichols [1939, p. 294] proclaimed that inferences about the dynamics of lava flows "can be determined only if it is known whether the flow was turbulent or laminar." A slight overstatement of the case for viscous fluid flow precedes this insightful remark, that "gravity does not succeed in making the liquid of low viscosity flow more rapidly than the more viscous liquid, because the liquid of low viscosity uses up energy in turbulence..." When a free, unconfined upper surface is present, additional volumetric flow rate can always be used to increase the mean flow velocity, although this is not as efficient for turbulent flows. Inferences drawn by Nichols for the Alika flow of the 1919 Mauna Loa eruption and a distal segment of the McCartys flow in New Mexico included a laminar flow regime and flow advance rates of about $2 \mathrm{~m} / \mathrm{s}$ and $0.2 \mathrm{~m} / \mathrm{s}$, respectively.

Numerous works treating lava emplacement with the concept of laminar, viscous fluid flow have appeared since Nichols' publication. With the aid of more detailed observations of basaltic lava flow emplacement, we know today that the concept of laminar flow with all elements moving in parallel is certainly not always valid. In addition, advance rates for many basaltic lava flows have been significantly greater than the range of values inferred by Nichols.

The classical view of turbulence in fluid flow features statistically correlated, time-dependent fluctuations in the components of flow velocity. We still cannot make the assertion of turbulence in lava flows in the classical sense. However, pure 
Laminar How is clearly somewhat of a special case due to mixing. disruption of streamlines, irregular lowbed topography, breaks in slope, and other factors [see Crisp and Baloga, $1994 \mid$. It is unfortunate that the term "disrupted flow" [Dangherty and Franzini. 1"ing has never hoen widelv areepted in the scientilic literature for naturally occurring conditions between pure laminar flow and classical turbulence.

Fickl evidence and several critical observations indicate that the emplacement of the $1800-1801$ Hualalai and 1823 Kilaued flows resembled a rapid flooding by lava, rather than a relatively slow-moving. laminar advance of a cooling and crystallizing viscous thuid. In this work we resurrect an approach that has resided in desuetude for more than half a century and propose a tloodlike model for low-viscosity, high effusion rate Hows. We show that a reconstruction of the flow dynamics provides quantitative and qualitative results that are consistent with several types of field evidenee. The dynamics of such flows are scaled for gravity differences to illustrate the influence of a planetary setting on these unique terrestrial analogs.

\section{Geological Observations of the 1801 and 1823 Lava Flows}

Reconstructing the dynamics of flow emplacement requires several types of geological observations to ascertain the important physical processes that governed flow behavior. These observations include the fluid behavior of the molten lava at various stations along the path of the flow, field evidence on tlow behavior and fluidity, and dimensional and morphologic comsiderations. Details of the known and inferred properties of the flows considered here are summarized betow.

\section{The 1801 Hualalai Lava Flow}

The geology of this flow, also known as the Kaupulehu flow, is described in detail by Richter and Murata [1961], McGetchin and Eichelberger [1975]. Jackson et al. [1981], and Cuest et al. [1905]. Brietly, it is an alkalic basaltic at flow, having abundant channels, erupted from a fissure zone at about $1700 \mathrm{~m}$ clevation along the northwest rift of Hualalai volcano (Figure 1). The flow trends down slope to the north for a distance of about $15 \mathrm{~km}$ to the sea and, from there, about another $5-6 \mathrm{~km}$ into the ocean. The remaining deposit of lava is relatively thin at the margins of the flow with thicknesses of $2-3 \mathrm{~m}$ near its source vent and thickening only slightly at the margins to about $5-8 \mathrm{~m}$ near the ocean.

The 1801 flow is remarkable for its beds of xenolith nodules [Richter and Murata. 1961]. The xenoliths appear to have been emplaced as a cobble lag deposit and, in some places, as an overbank levee deposit [Gatst et al. 1995]. Rinds of lava on the nodules (Figure 2) indicate that the effective viscosity of the host lava during nodule emplacement was extremely low, of the order of $10^{-}-10^{3} \mathrm{P}\left(10^{1}-10^{2} \mathrm{~Pa}\right.$ s) [Mo Getchin et al., 1976]. Drainage is similar at all locations along the path of the flow where nodule beds are exposed. There is no evidence from the rinds for a significant systematic change in viscosity, or other rheologic parameters, with distance from the vent.

The flow tratversed the $15 \mathrm{~km}$ from the vent to the sea extremely rapidly. The timescale for the development of a significant crust is typically tens of minutes to a few hours [Crisp and Baloga, 1990)]. The lack of any significant crust on the flow suggests an emplacement time of that order. This inference is also supported by the documented time of approximatcly 1 hour quoted by Ellis [1842]. Cillest et al. [1995] indepen- dently estimate a flow velocity near the vent of at least $10 \mathrm{~m} \mathrm{~s}$ ', based upon the uphill liow of lava around a preexisting cone.

Lava channels near the heds of xenolith nodules can be quite large, up to $80 \mathrm{~m}$ across and $18 \mathrm{~m}$ deep (Figure 3). The drainage of the nori. ${ }^{-1}$. . nde both toward the upper reach of the flow and betow the highway, the presence of lava overspills, and the lack of a dramatic longitudinal increase in flow thickness, all provide evidence for a very low viscosity host fluid.

\section{The 1823 Kilauea Lava Flow}

The 1823 Keaiwa lava flow from the southwest rift zone of Kilauea volcano also possesses several remarkable features that suggest unusual cruption conditions [Stearns, 1926]. The flow is a basaltic tholeiitic pahoehoe lava flow that changes to a slabby ad surface at its distal margins. The flow vent is a linear feature called the Great Crack and is between 1 and $10 \mathrm{~m}$ wide (in most places averaging about $3 \mathrm{~m}$ ) and about $10 \mathrm{~km}$ in length (Figure 4). The flow near its source vent is thin, ranging from 2 to $30 \mathrm{~cm}$. Nowhere does the flow thickness exceed about $2 \mathrm{~m}$ [Steams, 1926] and $1.5 \mathrm{~m}$ is a reasonable estimate of the average. The flow traveled down slope at an angle to its source vent. Thus flow lengths vary from 1.5 to about $5 \mathrm{~km}$. The total area of the flow is about $25 \mathrm{~km}^{2}$, of which some unknown but probably small fraction is submarine [Stearns, 1926].

Ohservations of the eruption testify that lava issued from the Great Crack very rapidly in the form of a sheet that quickly flowed to the ocean, overwhelming a village and overtaking flecing natives [Ellis, 1842; Stearns, 1926]. Although this flow contains no xenoliths, accretionary balls of lava display very thin (centimeter size or smaller) layers of lava plastering, suggesting a very fluid magma. During the eruption, flow advance was so rapid that the lava actually overrode a preexisting cone, as occurred near the vent of the 1801 Hualalai lava fow. The lava apparently went about $11 \mathrm{~m}$ up the side of a preflow cinder cone (called the lava-plastered cones [Stearns, 1926]). This evidence suggests velocities of flow of at least $15 \mathrm{~m} \mathrm{~s}{ }^{1}, \mathrm{com}$ parable to the velocity inferred for the 1801 Hualalai lava flow [Guest et al., 1995].

\section{Elementary Flood Model}

The low viscosity of these lava flows and their rapid rates of advance suggests a type of geologic mass movement more like a precipitous flooding of lava than a relatively slow-moving, viscous fluid flow. The residual deposits show that, for practical purposes, viscosity changes along the flow paths were insignificant in hoth cases. This contrasts with other basaltic flows, such as the $1 \mathrm{~A}$ flow from the 1984 Mauna Loa eruption, that underwent a rheologic change of several orders of magnitude during the 5 days of advance [Crisp et al., 1994; Moore, 1987]. Crystallization of microlites occurred during the advance of the Mauna Loa $1 \mathrm{~A}$ flow, as well as the formation of a thick crust. As the viscosity increased toward the front of the flow, the thickness increased dramatically to $25 \mathrm{~m}$ in places. Although perhaps not as dramatic, many of the lobes of the Puu Oo eruption showed significant thickening with distance from the vent and a slowing of the advance rate that has been attributed to rheologic changes [Fink and Zimbelman, 1990]. Unlike the 1801 and 1823 eruptions, these flows were emplaced over periods, typically, of a few days.

For both the Mauna Loa $1 \mathrm{~A}$ eruption and many of the lobate $\mathrm{Pu}$ Oo flows, the duration of emplacement was sufliciently long that a significant crustal component formed on top 


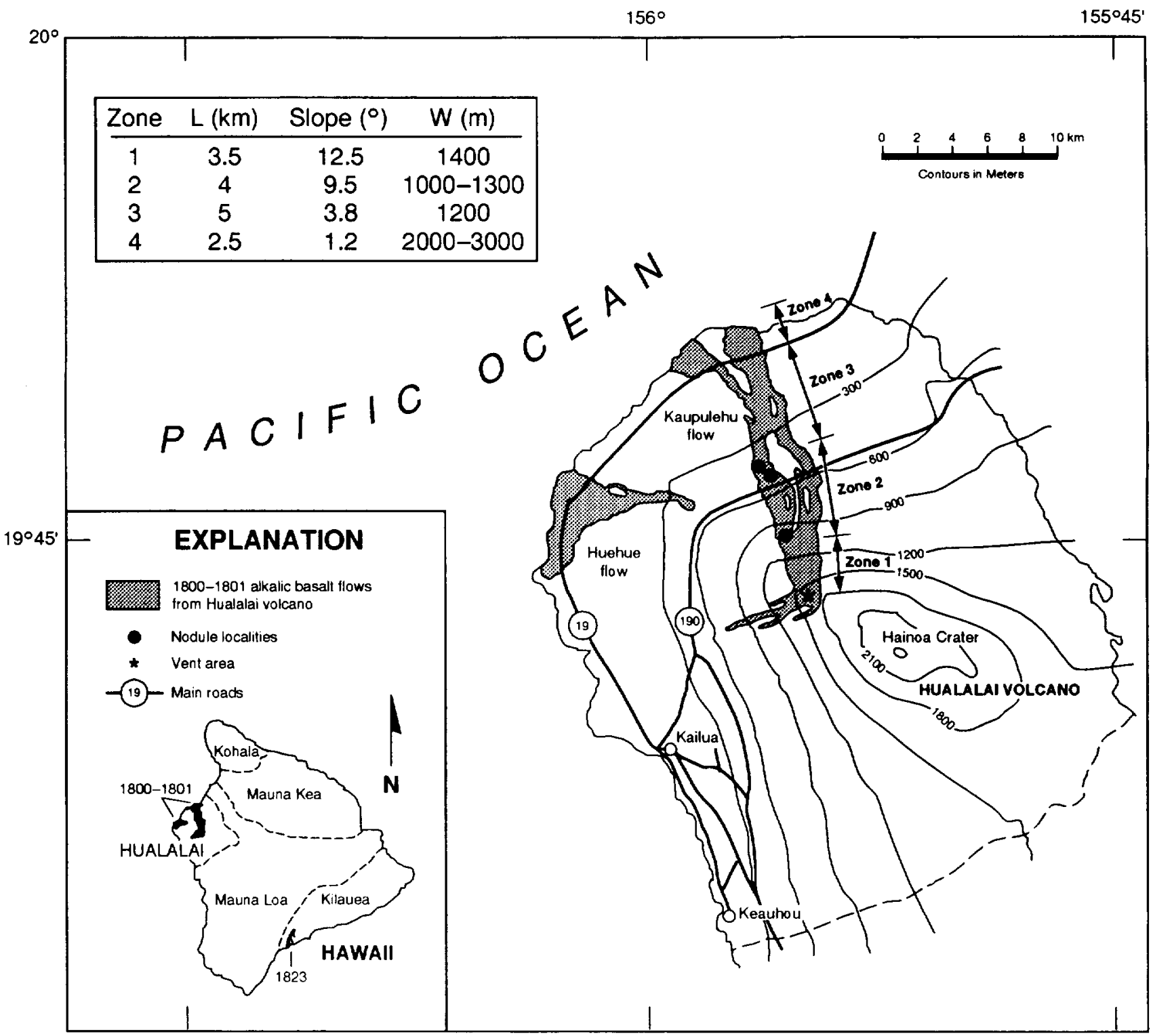

Figure 1. Sketch map of the island of Hawaii showing the 1801 Hualalai lava flow. After Guest et al. [1995]. Measurements of reach length $(L)$, flow width $(W)$, and slope $(\theta)$ were made from air photos and 7.5 min U.S. Geol. Survey topographic maps of the Kiholo Quadrangle and the Kailua Quadrangle.

of a hot inner core. Once such a flow becomes established, the streamlines within the flow tend to become parallel, although some mixing and disruption often occurs, particularly when time-dependent or intermittent effects are present. Cracking, mixing, and other processes expose the inner core causing an important and significant thermal loss [Crisp and Baloga, 1990; Crisp et al., 1994; Crisp and Baloga, 1994|, but for the most part the inner core of such slowly advancing, viscous flows remains highly insulated from radiative losses.

Field observations of the 1801 and the 1823 Hows indicate that the emplacement was rapid enough to prevent a significant crustal component from building up. It is likely that a high degree of mixing continuously brought hot inner layers to the surface. However, emplacement was so rapid that neither the formation of a thick crustal layer or a marked change in the bulk viscosity was able to occur, except for lava from the very final stages of discharge.
Fluid dynamic effects observed in a variety of different geologic mass movements were present in these flows, however. Run-up is evident in both the 1801 and 1823 flows. The xenolithic nodules are most evident, as one would expect from a hydraulic type of flow, at breaks in slope [Allen, 1970]. The nodules themselves present the appearance of hydraulically worked cobbles in a lag deposit. The overall dimensions of the Hualatai flows show a corresponding widening as the underlying slope lessens. Field inspection provides the clear impression that the directions of flow and the locations of the emplaced margins were controlled largely by the preexisting topography as opposed to internal physical changes in the lava itself.

To describe the dynamics of these flows, we assume the local conservation of fluid volume

$$
w \frac{\partial h}{d t}+\frac{\partial Q}{\partial x}=0
$$




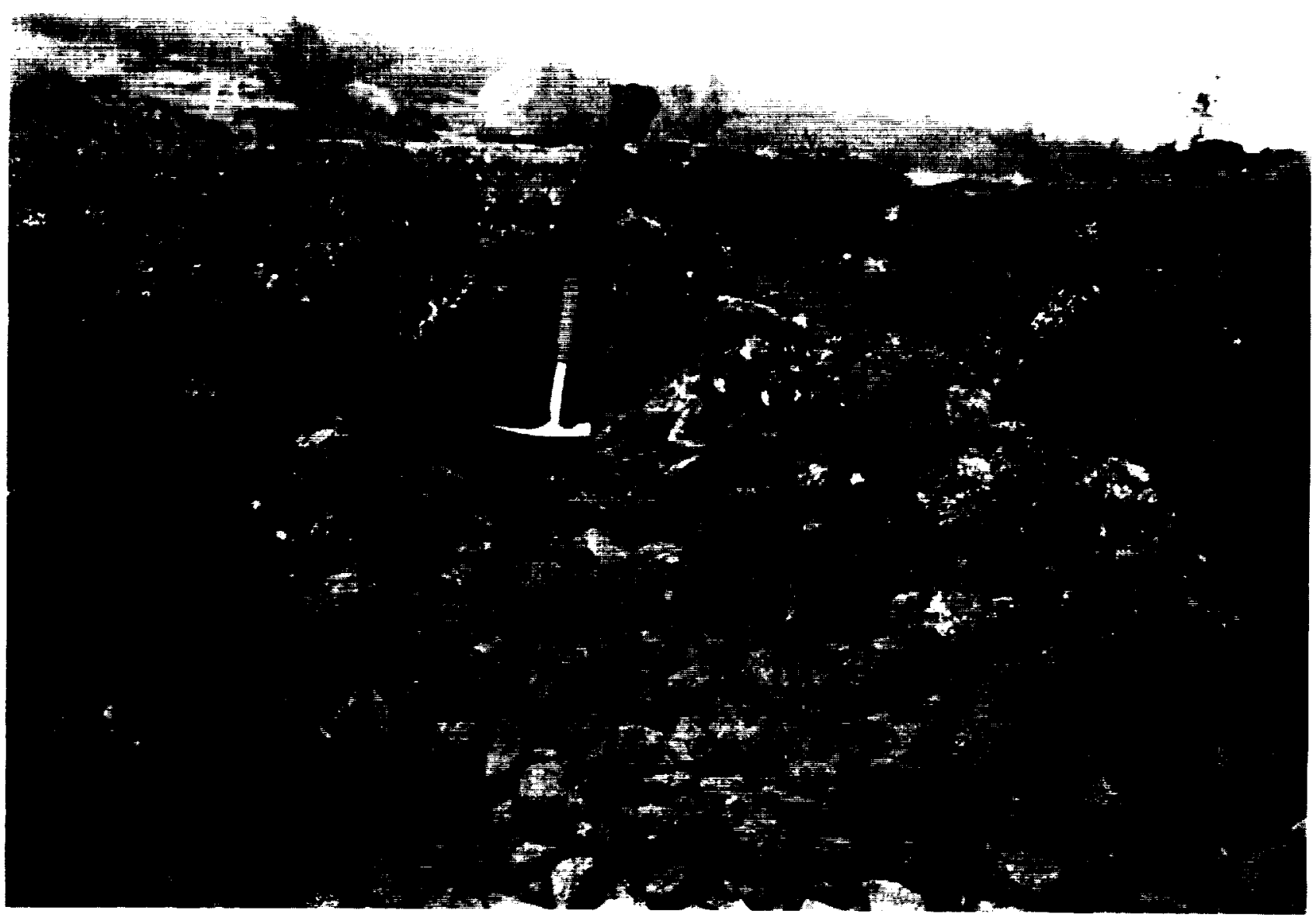

Figure 2. Xenolith nodules found in the 1801 Hualalat bava llow. Thin rinds (about $1 \mathrm{~mm}$ or less) of host lava on the nodules suggests an extremely fuid, low-viscosity lava.

where $h$ is the depth of the flow, 1 is the width, $Q$ is the local volumetric llow rate, $x$ represents the distance along the path of the llow, and $t$ is lime. The volumetric llow rate is the product of the cross-sectionat anea of the flow times the mean velecity. Equation (1) simply reepures any spatial change in the local flow rate to be compensated by a local thickening of the tlow with lime.

The generic statement of volume conservation in (1) provides little practical value until the form of the volumetric flow ratce is explicilly determined by theoretical or empirical means. Gencrally, a lowrate preseription features a dependence on the underlying slope. the depth of the flow, gravity, and parameters that characterize the resistance of the medium to flow (c.g. viscosity and yickd strength).

In spite of the field evidence for a highly fluid lava, one might conjecture all average flow velocity of the form

$$
\|=\frac{1 p ! y \sin \theta t h^{2}}{3} \quad \mu
$$

characteristic of a laminar Newtomian flow. Where $p$ is the density, $g$ is gravity, $\theta$ is the slope, and $\mu$ is the viscosity. Equation (2) in effect defines a focal flowrate needed to make (1) an explicit differential equation for h. Applications of (2) and (1) to lava thows have been presented in the literature [e.g., Baloga and Pioni. | 986 .

Fluid thow governed by (2) may be characterized by the dimensionless Reynolds number

$$
R_{c}=\stackrel{m h}{\mu} .
$$

As a reference, laboratory studies of tluid flow in pepes have shown that the transition from laminar flow to classical turbulence occurs for Reynolds numbers in the range from 2000 to 3000. For higher values, the onset of classical turbulence is difficult to prevent, regardless of the geometry. For lower values, the thow has insufficient energy to mantain turbulence.

We can examine the platusibility of (2) for the 1801 flow using the slope meatsurements that appear in Table 1. Ficld observations suggest a minimum thickness in the central part of the flow of at least $5 \mathrm{~m}$. Mo (idchin and Eichelberger [1975] and Mc (iotchin et al. [1976] arrived at an eruption viscosity of $10^{\prime}-10^{-2}$ Pa s using petrologic constraints and a range of plausible cruption temperatures and volatile contents.

Table 2 shows hypothetical flow velocities given by (2) and corresponding Reynolds numbers for the 1801 flow using a conservative estimate of $5 \mathrm{~m}$ for the flow depth, $10^{2} \mathrm{~Pa}$ s for the viscosity, and a density of $2.6 \times 10^{-7} \mathrm{~kg} / \mathrm{m}^{3}$. These elementary compulations clearly indicatc that (2) is a poor choice. The extremely high flow velocitics and Reynolds numbers are grosily inconsistent with the concept of a laminar Newtonian fluid flow, at least for describing the large-scale features of the loul How.

Many geologic mass movements and fast-moving fluids bearing various kinds of loadlings or suspensions exhibit a non- 


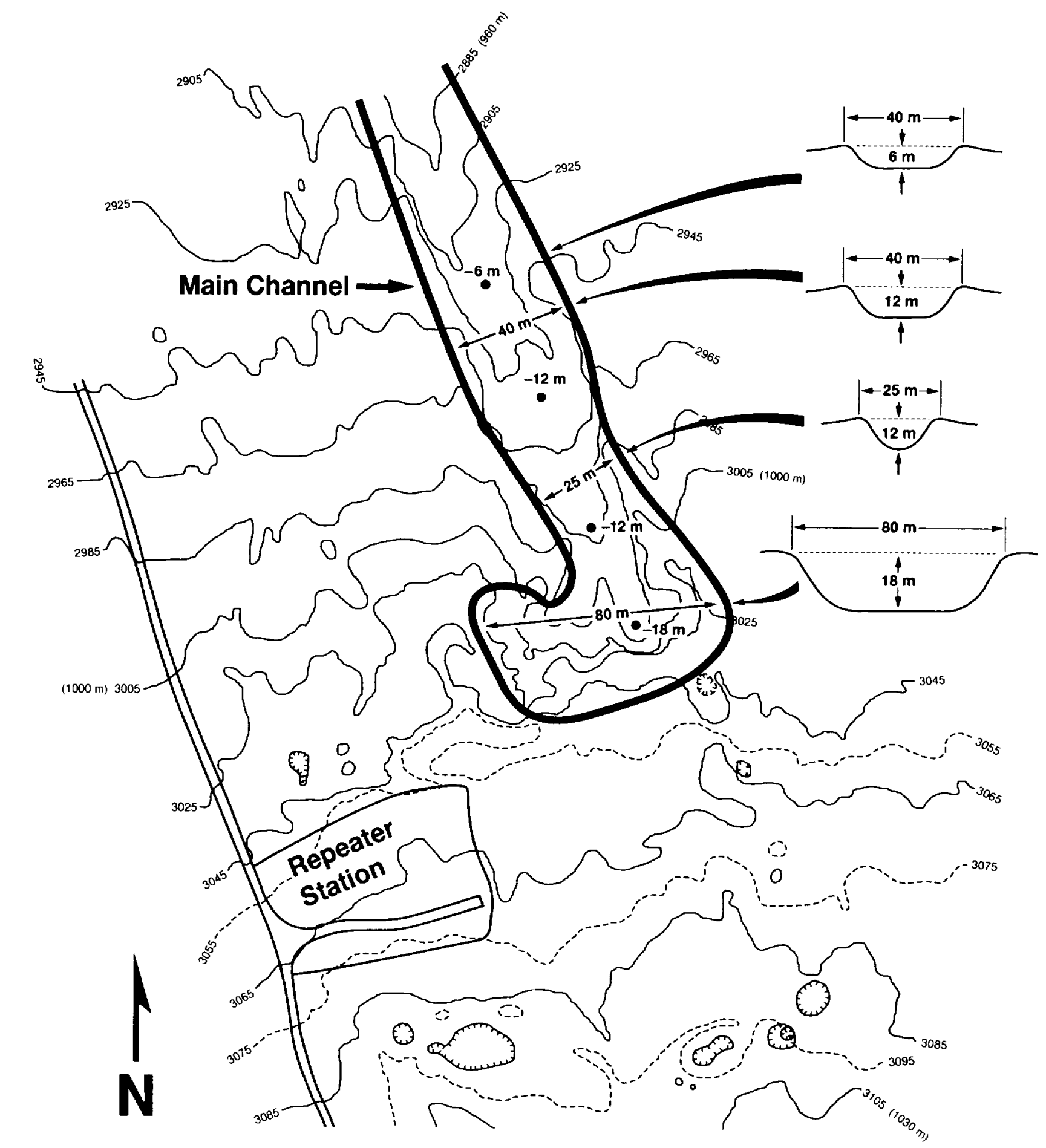
100

METEGS

Contours in Feet

Figure 3. Topographic map of the area near the repeater station showing the dimensions of a huge lava channel in which bedded layers of xenolith nodules are found. Channel dimensions taken from map, supplemented by field measurements. Topography from Jackson and Clague' [1982].

Newtonian or quasi-Newtonian behavior with a flow velocity given approximately by

$$
u=\sqrt[h g \sin \theta]{C_{f}}
$$

where $C$, is a dimensionless friction coefficient that is determined empirically, or quasi-empirically, and may depend somewhat on the nature of the suspended material and the roughness of the underlying flowbed or the lateral confinement.

For simplicity, we have expressed the mean velocity in a 


\section{Keaiwa Flow Kilauea Volcano, Hawaii}

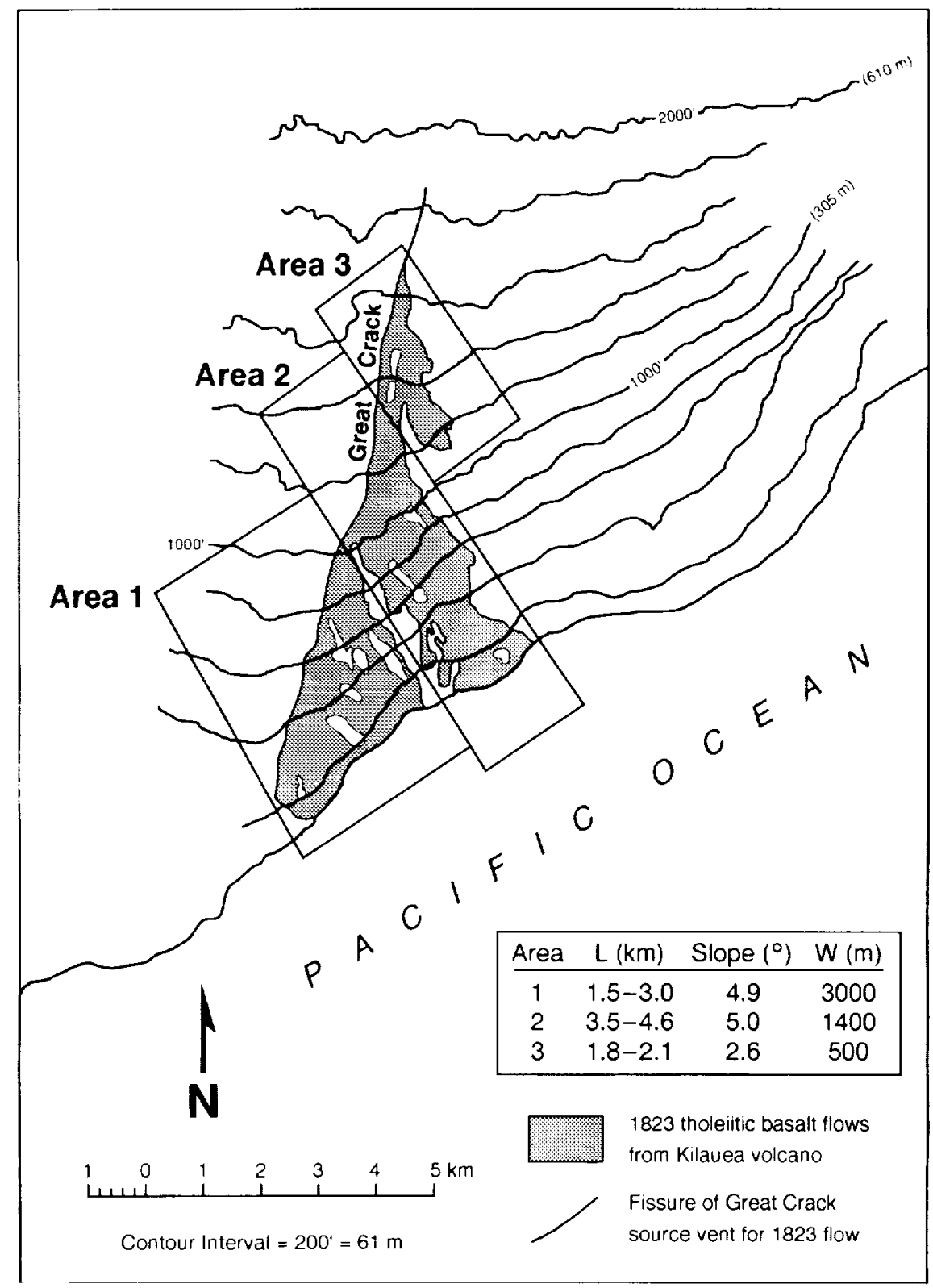

Figure 4. Sketch map of the 1823 Kilauea lava tlow. Flow crupled from long fissure vent (Great (rack) and was very fluid. Dimensional measurements were made from the $1: 100,000$ U.S. Geological Survey topographic map: "Hawaii Volcanoes National Park and Vicinity" ( 1986 ). Estimates of the flow velocily reported by Gitest 't al. [1995] were made near the northermmost kipuka in area 2.

conventional form [sec Komar. [980). equation (6)] that makes C, dimensionless. Some authors [e.g. Daugherty and Franzini. $106.5]$ use a slightly different convention featuring a numerical prefictor. usually 2 , in the numerator of (4), but (', remains dimensionless. Other specifications like (4) feature explicitly physical variables related to the resistance to flow. sucll ats the average density or radius of transported particles, thus making

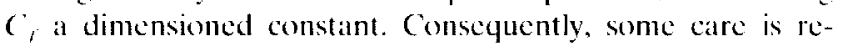
quired in comparing the flow resistance parameters of different geologic mass movements.

This general form of the llow rate has appeared in the scientitic literature for over 200 years in connection with
Table 1. Dimensional Datlat and (omputed (hanges for the lsol Hualalai Lava How

\begin{tabular}{|c|c|c|c|c|c|}
\hline Zonc & L. hm & $W, \mathrm{~m}$ & $\begin{array}{l}\text { Slope. } \\
\text { degg }\end{array}$ & $h h$ & \|\|$\|$, \\
\hline I & 3.5 & 1400 & 12.5 & 1 & 1 \\
\hline 2 & 4 & 1150 & 9.5 & 1.25 & 0.98 \\
\hline 3 & 5 & $12(10)$ & 3.8 & 1.64 & 0.71 \\
\hline 4 & 2.5 & 25010 & 1.2 & 1.48 & 0.38 \\
\hline
\end{tabular}

Swe Figure 1 for definition of zoncs. Rattios of flow thickn ass $(h / h$, and flow velocity ( $(1, u$,$) , relative to relerence values for 7$ me 1 , are computed from the lava flood model. 
Table 2. Hypothetical Flow Velocities and Reynolds Numbers for 1801 Ilualalai Flow

\begin{tabular}{ccc}
\hline Zonc & a. m/s & $R_{0}$ \\
\hline 1 & 467 & $6 \times 10^{+}$ \\
2 & 358 & $5 \times 10^{4}$ \\
3 & 144 & $2 \times 10^{4}$ \\
4 & 45 & $6 \times 10^{3}$
\end{tabular}

Flow velocities and Reynolds numbers are inconsistem with the assumption of a lamior Newlonian flow. Sec text for method of computation and parameters.

Chery's formulation of flooding by water in a confined channel. Nevertheless, modern treatments of the complex geologic materials in lahars, debris flows, and mud flows, still cmbrace a formulation like (4) and try to reline the description with advances in theory or the use of empirical datta. Frequently, these studies focus on adjustments to the power liaw dependence of the flow rate on the depth of the flow, the appropriate value for the friction coefficient, and the dependence of the friction coefficient on the dimensions of entrained particles, and similar considerations.

A small sampling of literature results provides an indication of the magnitude of the friction coefficients that might he anticipated for different types of geologic mass movements that have been modeled by a form as shown in (4). In a comparable formulation for the ascent dynamics of matars and diatremes, McGethin and Ullich [1973] have used a friction cosflicient of 0.1. Komar [1980] cited a value of 0.0015 for sediment-daden turbulent water flooding. For water flowing in smooth cement channels, Jeffreys [1925] obtained the empirical valuc of $11.0(125$. at remarkable result which has withstood the test of time [Whitham, 1974] in spite of significant advantes in both hydrology and metrology. With a comparable formulation, Weir [1982] (see equation (10) and Table 8 in that reference, noting that $C_{r}$ is approximately $y / b^{2}$ ) has ohtained values approximatcly equivalent to the range 0.011 to 1 from a kinematic watre theory for the movement of lithars. For certain types of debris flows, Takahashi [1980] (see equation (19) and the subsequent discussion in that reference) has obtained 0.577 from empirical studies.

We propose the flow rate form shown in (4) for lava flows that were emplaced by rapid flooding. rather than laminar, viscous fluid flow. The governing time-dependent equation for the flooding of lava becones

$$
\left.w_{i l}^{i h}+i d(h w)^{i h g} \sin \theta\right)=0 .
$$

In general, this equation must be supplemented by an appropriate boundary condition to evaluate the influence of timedependent changes in the effusion rate on the evolving downstream flow thickness. When detated information about vent conditions is not avalable, steady state solutions maly be assumed as an approximation. This makes the first term in (5) irrelevant, but we lose the ability to explain thickness changes with time at fixed stations along the path of the flow.

At present, there is no experience with the application of such a formulation to lava llows. Specifically, the friction coefficient appearing in the denominator is completely unknown and the power law describing the response of the flow rate to the depth and underlying slope is postulated. Consequently. our approach is to apply this mosel to the flows and compare the results with independent field checks for consistency. We will also compare the results with the experience documented in the geologic literature for other types of mass movements with similar governing equations.

\section{Dynamics of the 1801 Flow}

The $1 \times(3)$ eruption produced lava flows that overran four relatively distinct zones on the volcano during transit to the ocean. These zones are indicated on the sketch map appearing as Figure 1. Measurements of the length of each reach $(L)$, the width $(W)$, and slope $(\theta)$ were made from air photes superimposed on U.S. Geologic Survey topographic maps. As seen in Figure 1 and Table 1 , the width and slope are roughly constant in each zonc. We assume that the outer matrgins of the llow were emplaced during an carly phase of the eruption and that the channels found in all reaches were formed subsequently.

Becatuse no other information is available, the eruption rate is considered to be constant during the early phase of the cruption. With no time-dependent effects in (5), the flow rate becomes a conserved quantity $\left(=O_{0}\right)$ along the flow path. Thus

$$
Q_{11}:-\|_{i} h_{i} w_{i}
$$

where the subseript $i$ indicates the value of the variable in zone $i$.

Equations (4) and (6) proviale an immediate constraint on the ratio of the thickness of the flow in each zone given by

$$
\begin{aligned}
& h_{i} \\
& h_{r}
\end{aligned}=\left(\begin{array}{l}
w_{r} \\
w_{i}
\end{array}\right)^{23}\left(\begin{array}{l}
\sin \theta_{i} \\
\sin \theta_{i}
\end{array}\right)^{13}
$$

where $i$ denotes the zone of interest and $r$ indicates a reference zone. The reference values are taken as those of zone 1 , although any zone could be chosen.

Table 1 shows the relative thicknesses in each of the zones batsed on the measured values of the flow widths and slopes. This type of llow model produces a longitudinal thickness profile that is relatively flat in spite of the significant changes in slope and flow width in the different anes. When the underlying slope variations and lateral spreading of the flow are laken into account, we expect only a modest thickening along the flow path according to the results in Table 1.

We can also derive the relative velocity of the flow in each of the rones by substituting (7) into (4).

$$
u_{i}=\frac{h_{r} w_{r}}{h_{i} w_{i}}=\left(w_{r} \sin \theta_{1} / w_{i} \sin \theta_{i}\right)^{1 \cdot 3} .
$$

The relative flow velocitics are also shown in Table 1.

The predictions of llow thickness and velocity in Table 1 are only relative values based on volume conservation, the form of the llow rate, and geometric considerations. In effect, these predietions must be calibrated by independent information on reference vilues in one of the zones. If we had independent experience and knowledge of the friction coefficient. this would not be the case.

Ficld observations in zone 1 indicate that the flow must have been at least $5 \mathrm{~m}$ deep, presumahly during the early stage of the eruption. By using this estimate as the reference value, the flow thicknesses in the other zones are given by (7). The numerical thickness values are shown in Table 3. Although it is difficult to establish flow thicknesses from postemplacement 
Table 3. Reconstructed Dynamics for the 18011 Hualalai Lava Flow

\begin{tabular}{lcccc}
\hline & \multicolumn{4}{c}{ Zone 1 (Estimated) } \\
\cline { 2 - 5 } & $h \quad 5 \mathrm{~m}$ & $u=5 \mathrm{~m} / \mathrm{s}$ & $u=10 \mathrm{~m} / \mathrm{s}$ & $u=1.5 \mathrm{~m} / \mathrm{s}$ \\
\hline $\begin{array}{c}\text { Zonc 2 } \\
\text { (Computed) }\end{array}$ & 6.2 & 4.9 & 9.8 & 14.6 \\
$\begin{array}{c}\text { Zonc 3 } \\
\text { (Computed) }\end{array}$ & 8.2 & 3.5 & 7.1 & 10.6 \\
$\begin{array}{c}\text { Zone } 4 \\
\text { (Computed) }\end{array}$ & 7.4 & 1.9 & 3.8 & 5.7 \\
$\begin{array}{c}\text { Transit timc. } \\
\text { min }\end{array}$ & 71 & 35 & 24 \\
Flow rate. \\
mis
\end{tabular}

Zone 1 values for thickness and velocity are estimated as described in text. All other values are computed from the lava flood model.

conditions, we consider the values in Table 3 to be consistent with ficld observations.

Guest et al. [1905] have estimated a minimum local fow velocity in zonc 1 to be at least $10 \mathrm{~m} / \mathrm{s}$. Using this as the reference value for $(8)$ gives the zonal flow velocities shown in Table 3. There are uncertainties in such field estimates, so Table 3 includes alternative reference choices $(5$ and $15 \mathrm{~m} / \mathrm{s}$ ) for the flow velocity in zone 1 and the corresponding downstream velocities. Based on the observations of Guest at al. [1995], we consider the middle value $(10 \mathrm{~m} / \mathrm{s})$ to be the best estimate of the three alternatives shown in Table 3.

Three important characteristics of the emplacement can be reconstructed from the formulation above, namely, total transit time from the vent to the ocean, the volumetric flow rate, and the friction coefficient. Values for each of these quantities with the three alternative reference velocities appear in Table 3. The transit time is computed from the relation

$$
\mathrm{l}=\sum_{1}^{+1} \boldsymbol{u}_{i}
$$

The hest estimate of the transit lime from the cratter to the ocean is about $35 \mathrm{~min}$, which is consistent with the recorded observations [ $2: l i s, 1842]$. Such a transit time is also consistent with the lack of a significant crust formed on the surface of the flow. For times much longer than an hour, we would expect to find some evidence for a significant crust in the distal parts of the flow, and this was not observed in the field.

The best estimate of the flow rate is $7 \times 10^{4} \mathrm{~m}^{3} / \mathrm{s}$. Even the lowest value in Table 3 is more than a full order of magnitude higher than the estimated peak of $3000 \mathrm{~m}^{3} \mathrm{~s} 1$ for the 1950) Mauna Loa eruption [Malin, 1980]. The volcanology literature is replete with estimates of eruption rates. However, these estimates are usually time-averaged over the entire duration of eruption, so one rarely finds values approaching the 1950 Mauna Loa value or the result we have obtained for Hualalai.

The heretofore unknown friction coefficient was determined by the equation

$$
C_{t}=\frac{g \sin \theta h}{a^{2}} .
$$

It may be recalled that the range of values shown in Table 3 for the friction coefficient is common in the literature for lahars, debris flows, and sediment-laden water floods, where similar formulations of the flow rate have been used.

Perhaps the most convincing test of this formulation concerns the unusually large channels of the Hualalai flow complex. Near the repeater station, the largest channel is approximatcly rectangular in shape with a width that narrows to about $40 \mathrm{~m}$ and a depth of $18 \mathrm{~m}$ (See Figure 3). Field observations indicate that this channel must have been completely filled at some point during the eruption. Moreover, there is no field evidence for a ponding or staging area along the path of the flow where lava could have accumulated prior to a catastrophic release.

We now examine the depth of flow in such a channel with the inferred eruption rates and friction coefficients. As a minimum, the channel depth must satisfy the constraint,

$$
h_{c}=\left(\begin{array}{l}
Q \\
w
\end{array}\right)^{2 / 3}\left(\begin{array}{c}
C_{l} \\
g \sin \theta
\end{array}\right)^{1 / 3}
$$

where $h_{t}$ is the depth of the channel, $w$ is the measured width of the channel, and $Q$ and $C$, are the inferred values from the previous analysis. If the entire flow rate was confined to such a channel, the computed depth of filling would be more than twice the measured depth for each of the flow rate/friction coefficient pairs shown in Table 3.

An alternative approach is to compute the flow rate and flow velocity necessary to fill such a channel. The results of these computations are shown in Table 4 . The flow rate in the channel is approximately one seventh of the previous estimates, although the velocity of flow in the channel remains very high.

We might suspect the flow in the channel to be laminar late in the eruption and attempt to abandon the flood model at this stage. Using the familiar formula for the average flow velocity shown in (2) with $\rho=2.6 \times 10^{3} \mathrm{~kg} / \mathrm{m}^{3}, g=10 \mathrm{~m} / \mathrm{s}^{2}, \theta=8$ degrees, $h=18 \mathrm{~m}$, and the conservative estimate $\mu=100 \mathrm{~Pa}$ s $(10(0) \mathrm{P})$, we obtain $u=3.9 \times 10^{3} \mathrm{~m} / \mathrm{s}$ and $R c:=2 \times 10^{\prime \prime}$. For this conjecture to be remotely viable, there would have to be new evidence for a viscosity at least 2 orders of magnitude higher than the McGetchin et al. [1976] estimate.

We consider this to be an important check on the consistency of the previous flow rate estimates. Basaltic eruptions often wane significantly in effusion rate from relatively high peak values established carly in the eruption. Channels typically form after the early phase of the eruption and it is unlikely that the entire flow rate was conducted through this solitary channel at the repeater station. Our flow rate estimate in the channel is consistent with the hypothesis of a high effusion rate carly in the eruption followed by a subsequent waning.

Given the total volume of lava that can be identified and associated with this eruption, it is not likely that high flow rates (approaching $10^{5} \mathrm{~m}^{3} / \mathrm{s}$ ) were maintained continuously for days

Table 4. Flow Rate and Velocity in Repeater Station Channel

\begin{tabular}{ccc}
\hline$c$, & $Q . \mathrm{m}^{3} / \mathrm{s}$ & $u, \mathrm{~m} / \mathrm{s}$ \\
\hline 0.42 & $5.5 \times 10^{3}$ & 7.6 \\
0.11 & $1.1 \times 10^{4}$ & 15.2 \\
0.05 & $1.6 \times 10^{4}$ & 22.8
\end{tabular}

Using the friction coefficient of previous computations and dimensional data for channel, the flow rates $(Q)$ and velocities (u) are required to fill the channel. 
or weeks. Otherwise, a much more massive edifice would have been constructed from the 1801 eruption. The flow rate in the channel at the repeater station supports a significant drop in the flow rate from the peak value established early in the eruption.

The relatively high velocities in the channel argue strongly for a highly agitated and forceful flow that would be necessary to suspend and transport the nodule load. Evidently, this occurred with such a highly mixed and agitated character that significant internal temperature gradients were prevented during the rapid delivery to the distal reaches of the flow. Indeed, the deposition of nodules in the deep channels supports the continued drop in the effusion rate as the eruption waned.

The cause of the unusually high volumetric flow rate featured by this eruption remains somewhat unclear at present. Guest et al. [1995] have attributed the high rate of discharge to the near-Newtonian theologic properties of the host lava during both eruption and emplacement. Alternatively, a summit crater about $250 \mathrm{~m}$ in diameter may have served as a reservoir for molten lava. Ficld evidence clearly suggests that crater wall collapse supplied at least some of exposed lava flows.

The overall dimensions of the flow and the behavior of the eruption are consistent with a dynamic model of lava flooding. The volumetric effusion rate during the carly stage of eruption appears to have been between $10^{4}$ and $10^{5} \mathrm{~m}^{3} / \mathrm{s}$. This rate is almost 2 orders of magnitude higher than the peak of the 1950 Mauna Loa eruption and is comparable to eruption rates conjectured in the literature for large planetary lava flows. The transit times from the vent to the ocean are also consistent with the lack of a surficial crust, the low viscosity of the host magma in the distal reaches, and the historical comments on the speed of advance of the flow. It is clear that such high effusion rates were not maintained for a long duration. The drop from the high values shown in Table 3 is supported by the significantly lower volumetric flow rates in the channel, as shown in Table 4. The waning character of the effusion rate is also supported by the deposition of nodules exposed in the channels.

\section{Dynamics of the 1823 Flow}

The 1823 flow can be analyzed in a similar manner. Figure 4 shows a sketch map of the flow complex and suggests treating the emplacement as three separate and distinct flows emerging from different parts of the fissure. In each area the flow deposits each have a single width and slope along the path of the flow from the Great Crack to the ocean. Flow continuity between the three areas cannot be applied as was done for the 1801 eruption because the lava did not advance from one area to the next. Consequently, the dynamics of emplacement for the 1823 flow cannot be reconstructed in as great detail.

Guest et al. [1995] have estimated a flow velocity of at least $15 \mathrm{~m} / \mathrm{s}$ in area 2 about a kilometer from the Great Crack. First, we compute the friction coefficient from the formula

$$
C_{l}=\frac{g \sin \theta h}{u^{2}}
$$

with the mean flow thickness taken as $1.5 \mathrm{~m}$ and the average slope as shown in Figure 4. This gives $C_{f}=0.0057$, a value similar to that of sediment-laden flooding by water [Komar, 1980]. If the estimated flow velocity is conservatively decreased to $10 \mathrm{~m} / \mathrm{s}$, the friction coefficient becomes 0.0128 , which is more typical of water.
The two velocity estimates ( 15 and $10 \mathrm{~m} / \mathrm{s}$ ) for area 2 correspond to transit times of $4.4 \mathrm{~min}$ and $6.7 \mathrm{~min}$ to the ocean. The flow velocity must have remained essentially constant along the flow path, as far as we know. The rapid emplacement must have resembled an advancing, highly turbulent, floodlike sheet. There was very little time for a crust or skin to form. The thinness and fluidity of this flow suggests that it would naturally follow the small-scale topography, thus mixing any cooler skin into the interior.

For area 2 we find the eruption rates of 21,000 and 14,000 $\mathrm{m}^{3} / \mathrm{s}$ for these two velocities estimates $(15$ and $10 \mathrm{~m} / \mathrm{s}$ ). These rates seem very high by present-day experience, but this is primarily due to the extent of the fissure (c.g., $1400 \mathrm{~m}$ parallel to the direction of flow) and the lateral width of the flow.

In area $\mathbf{I}$ the slope is only marginally different from that of area 2 . The same flow velocity estimates are likely to be reasonable for this area as well. This part of the flow complex probably added another $45,000 \mathrm{~m}^{3} / \mathrm{s}$ or $30,000 \mathrm{~m}^{3} / \mathrm{s}$ to the eruption rate for estimated flow velocities of $15 \mathrm{~m} / \mathrm{s}$ and $10 \mathrm{~m} / \mathrm{s}$, respectively.

Toward the upper part of the Great Crack in area 3, the slope is about a factor of 2 lower. Here the flood model can be used to estimate the flow velocity of area 3 . Based on the two friction coefficients derived above, we obtain estimates of 10.8 and $7.2 \mathrm{~m} / \mathrm{s}$, respectively, in area 3 . These results are also based on an average depth of $1.5 \mathrm{~m}$. These velocity estimates correspond to flow rates of 8100 and $5400 \mathrm{~m}^{3} / \mathrm{s}$ for area 3 .

The flood model is hardly essential for these computations. They are based primarily on the mapping of the flow, geometric considerations, and the field estimate of the velocity in one of the areas. We have used the model only to compute the friction coefficient and the velocity in area 3 , which is a rather minor contributor to the eruption rate.

The model does provide one very important aspect of support for these considerations. Specifically, the friction coefficient is about 10 or 20 times less than that obtained for the 1801 flow. Conceptually, this is qualitatively consistent with the lack of an appreciable load in the 1823 magma and an emplacement that is even more rapid than that of the Hualalai flows.

The conclusion we obtain for the 1823 flow is that it also had a very high eruption rate, probably at least $21,000 \mathrm{~m}^{3} / \mathrm{s}$. If the three segments of the fissure were fed simultaneously, which appears likely, the eruption rate could have been roughly 3 times as high. As with the 1801 flow, this high eruption rate probably persisted only for a short duration, perhaps on the order of tens of minutes or less.

\section{Scaling the Model for Planetary Applications}

We now consider some implications of the lava flooding model for volcanism in a planetary setting. As a basis of comparison, we consider the volumetric flow rates of a laminar Newtonian fluid (equation (13)) and the lava flood model (equation (14)):

$$
\begin{gathered}
Q=\frac{g \sin \theta h^{3} W}{3 v} \\
Q=\sqrt{\frac{g \sin \theta h}{C_{f}} h W .}
\end{gathered}
$$

To compare terrestrial analogs with lava flows in a planetary setting, we suppose that the eruption rate, preexisting topog- 
raphy, and rheological properties remain the same in both settings. Our chief aim is thus to examine the influence due solely to changes in gravity.

The following example provides a comparison between a lava flow on the Earth and the Moon. For cither of the models shown in (13) and (14), we oblain the relation

$$
g_{c} h_{c}^{3}=g_{m} h_{m}^{3}
$$

A priori, it is somewhat surprising that (15) holds for both the Newtonian flow rate based on a laminar flow and the flood model that is more characteristic of disrupted, possibly suspension-laden. turbulent flow. By rearranging (15), and substituting values for the gravity of the Earth and Moon, we find

$$
h_{m}=\left(g_{1} / g_{m}\right)^{1 / 3} h_{c}=1.82 h^{\prime} \cdot
$$

A comparable flow on the Moon has a thickness almost twice that of its terrestrial counterpart.

Why lower gravity produces systematically thicker flows on planetary bodies with lesser gravity is evident from the corresponding velocity scaling:

$$
u_{m}=\left(g_{m} / g_{t}\right)^{1 \cdot u_{t}}={ }_{1.82}
$$

Due to the lesser gravity on the Moon, a comparable flow would advance almost twice as slowly. For the same eruption rate and preexisting topography, the slower rate of advance is the cause of the corresponding thickness increase. Equation (17) is valid for both of the flow rate models under consideration.

These considerations suggest that the 1801 Hualalai flow could indeed be quatutitatively similar to lunar eruptions that produced the lava flows at Mare Imbrium and other lunar locations. Doubling the margin thicknesses of the 1801 flows to account for the lower gravity produces thicknesses comparable to those of certain flow lobes in Mare Imbrium and elsewhere on the lunar maria [Schaber et al., 1976].

At one point during the Hualalai eruption, the eentral depth in channels was at least $18 \mathrm{~m}$. Comparable, but sustained, eruption rates on the Moon or Mars could produce flows with thicknesses between 10 and $30 \mathrm{~m}$, just due to the lower value of gravity. Flow thicknesses in this range are abundant on the plains and shield volcanos on Mars and the lava flow lobes in Mare Imbrium. Unlike the Hualalai eruption, however, the volumes of many of the planetary flows are at least an order of magnitude larger than those of the Hualalai flow complex. The lava flood model suggests that one primary difference is that the duration of plimetary cruptions of this style persisted for orders of magnitude longer than their terrestrial analogs.

The high fluidities and high effusion rates of these terrestrial cruptions might be analogous to conditions that once existed on Mars. the Moon, and perhaps Io and Venus. Most lava flows that have been identified on these surfaces are probably I or 2 orders of magnitude thicker than the Keiawa lava flows, although some authors have argued for similar cruption rates. Our knowledge of planetary voleanism is limited by the resolution of available images. Flows analogous to those at Keiawa may indecd exist in numerous planetary settings, but they would not be discernable with existing data. Flows with a relief comparable to the 1823 flows, even with adjustments for gravitational scaling. would go largely undetected, even on the Moon. However, some thin lunar flows with vertical relief of the order of meters have been suggested by Ciredey [1975].
This consideration has been thought to be the basis for the scarcity of mappable flow lobes on the young lunar maria for some time [Schaber et al., 1976].

When plan form, vertical relief, and topographic slope could be distinguished for lava flows on planctary surfaces, many authors have used models based on laminar flow to infer eruption, emplacement, and rheologic conditions [c.g., Moore and Schaber, 1975; Zimbelman, 1985; Cattermole, 1990); LopesGautier; 1993, and references therein]. For the rapidly emplaced terrestrial analogs considered in this work, we have the benefit of knowing that they were rapidly emplaced. Plan form and vertical relief comparable to available planctary data would be of little assistance in choosing between a more conventional laminar model and the rapid emplacement model we have employed. However, future studies will investigate the existence of morphologic diagnostics indicative of a rapid emplacement phase in the early stage of a planetary eruption.

\section{Conclusions}

The planimetric form, dimensions, and general morphologic character of basaltic flows do not guarantee that viscous fluid dynamies for laminar flow are appropriate for describing the essential character of emplacement. We have evoked an elementary lava flooding model, similar to ones used for a wide variety of geologic mass movements, to explain the emplacement of low-viscosity lavas from eruptions with high effusion rates. Application of this approach to the 1801 flow of Hualalai and the 1823 flow of Kilauea produces quantitative results that are consistent with several types of field observations. The inferred eruption rates for these flows are rather high by present-day experience, ranging from $10^{3}$ to $10^{5} \mathrm{~m}^{3} / \mathrm{s}$. The friction coefficients obtained by this analysis are of the order of 10 - to 10 ', generally in the range anticipated from other types of geologic mass movements.

The 1801 Hualalai and 1823 Kilauea eruptions may indeed be terrestrial analogs for many planetary eruptions due to the high fluidity and eruption rates. Our analysis suggests that the eruptions of these terrestrial analogs must have heen very brief by planctary standards. Scaling of the terrestrial analogs for gravitational changes indicates that flow thicknesses would roughly double on the Moon, Mars, Mercury, and Io, with corresponding decreases in flow advance velocities. Judging by the large volumes of discernable lava flows on planctary surfaces, the durations of eruptions must have been orders of magnitude longer than these unique terrestrial counterparts.

The transport model appearing in (1) relies on the assumption that the volume of a fluid element is a conserved quantity during emplacement. Various field and theoretical studies indicate that volume conservation may be only an approximation during the emplacement of a flow. Different aspects of this issue are given by, for example, Moore [1987]. Moore [1982], Stasiuk et al. [1993], and Wadge [1981]. One natural extension of the model presented here is the addition of a ratce term to (1) to describe differences between the erupted and postemplacement volumes. We will reserve this extension lor future studies.

Rapidly moving, highly fluid terrestrial lava flows may be less rare than is commonly thought. An unusually fast-moving, highly fluid flow with yet another composition was associated with the 1977 eruption of the Mount Niragongo volcano in Zaire [Tazieff, 1977]. A perched lava lake of nephelinite composition was very rapidly dritined in less than an hour. This 
massive effusion resulted in flows with average velocity estimates of about $10-15 \mathrm{~m} / \mathrm{s}$ and velocities early in the drainage may have been significantly higher. This cruption may have been analogous to the $1800-1801$ Kaupulehu eruption in that lava flows appear to have been fed, at least in part, by the rapid draining of a topographically perched lava lake.

We expect the lava flooding approach to be appropriate for other fluid lava flows that are emplaced too rapidly for laminar flow conditions to prevail. When a transit time or an independent flow velocity estimate can be obtained, morphologic data can be used to reconstruct the dynamics of the flow, as shown in this work. When a transit time or an independent velocity estimate cannot be obtaincd, a crude reconstruction of flow dynamics may be conjectured by using the friction coefficients obtained here and in future applications.

Acknowledgments. The authors express sinere gratitude for the thorough and insightful comments by J. Fink, H. Pinkerton, and $H$. J. Moore. Discussions and collaborative observations with G. J. Taylor and R. Greelcy are deeply appreciated. This work was supported by the NASA Planetary Geology and Geophysics program. Participation by P.D.S. represents LPI contribution 865.

\section{References}

Allen J. R. L., Physical Processes of Sedimentation, $248 \mathrm{pp}$., Allen and Unwin, Winchester, Mass., 1970.

Baloga, S., and D. Pieri, Time-dependent profiles of lava Hows, $J$. Geophys. Res., 91, 9543-9552, 1986.

Cattermole, P., Volcanic flow development at Alba Patera, Mars, Icarus, 83, 453-493, 1990).

Crisp, J., and S. Baloga, A model for lava flows with two thermal components, J. Geophys. Re's., 95, 1255-1270, 1990.

Crisp, J., and S. Baloga, Influence of erystallization and entrainment of cooler material on the emplacement of basalitic a lava flows, $J$. Geophys. Res., 99, 11,819-11,831, 1994.

Crisp, J., K. V. Cashman, J. A. Bonini, S. B. Hougen, and D. C. Pieri, Crystallization history of the 1984 Mauna Loa lava flow, J. Gerplys. Res., 99. 7177-7198, 1994.

Daugherty, R. L., and J. B. Franzini, Fluid Mechanics With Enginering Applications, p. 62, McGraw-Hill, New York, 1965.

Ellis, W., Polynesian Researches, Peter Jackson, Late Fisher, London, 1842

Fink, J., and J. Zimbelman, Longitudinal variations in rheological properties of lavas: Puu Oo basalt flows, Kilauea volcano, Hawaii, in Lava Flows and Domes. Emplacement Mechanisms and Hazard Implications, pp. 157-173. Springer-Verlag, New York, 1990.

Greeley, R., A model for the emplacement of lunar basin-filling hasalts (abstract), in Lunar Science VI, pp. 309-3](0, lunar Sci. Inst., Houston, Tex., 1975.

Guest, J. E., P. D. Spudis, R. Gresley, G. J. Taylor, and S. M. Baloga, Emplacement of xenolith nodules in the Kaupulehu lava flow, Hualalai Volcano, Hawaii, Bull. Volcanel., 57, 179-184, 1995.

Jackson, E. D., and D. A. Clague, Map showing distribution of the nodule beds of the $180(18-1801$ Kaupulehu flow of Hualalai volcano, Hawaii, U.S. Geol. Sun Misc. Ficld Stud. Map, MF-1355, 1982.

Jackson, E. D., D. A. Clague, E. Engleman, W. B. Friesen, and D Norton, Xenoliths in the alkalic basalt flows from Hualalai volcano, Hawaii, U.S. Geol. Sun: Open File Rep., 81-10.31, 32 pp., 1981.

Jeffreys, $H$., The flow of water in an inclined channel of rectangular section, Philos. Mag., 49, 793-8(17, 1925.
Komar, P. D., Modes of sediment transport in channelized water flows with ramifications to the erosion of Martian outflow channels, Karus, 42, 317-329, 1980.

Lopes-Gatutier, R. M. C., Extraterrestrial lava flows, in Active Lavas. Monitoring and Control, edited by C. Kilburn and G. Luongo. chap. 4, pp. 1117-144, Univ. College Press, London, 1993.

Malin, M. C. L.engths of Hawaiian lava flows, Goology, 8, 306-308, 1980.

McGetchin, T. R., and J. Eichelherger, Emplacement of the 1801 Hualalai lava How. Hawaii, Los Alamos Sci. Lab. Rep. L.A-5956-PR. pp. 77-82, Solid Earth Geosci. Res. Activ., Los Alamos Sci. Lah., Los Alamos, N. M., 1975.

McGetchin. T. R, and G. W. Ullrich, Xenoliths in maars and diatremes with inferences for the Moon, Mars, and Venus, J. Geophys. Res., 78, 1833-1853, 1973.

McGetchin, T., R. Widdicombe, J. Neudecker, and J. Eichelberger, Emplacement of the 1801 Hualalai lava flow and laboratory simulation of Mauna loa flow (abstract), Eos Trans. $A(i U, .57(4), 344$. 1976.

Moore, H. J., A geological evaluation of proposed lava diversion harriers for the NOAA Mauna Loa Observatory. Mauna Loa Volcano. Hawaii, and some recommendations, U.S. Gool. Sum. Open File Rep. 82-3/4, 17 pp. 1982.

Moore, H. J., Preliminary estimates of the rheological properties of 1984 Matuna Loa lava, U.S. Geol. Sun: Prof. Pap.. 1350, 1569-1588, 1987.

Moore, H. J., and G. G. Schaber, An estimate of yield strength of the Imbrium lava flows, Proc. Lumar. Sci. Comf., 6m, 101-118, 1975.

Nichols. R. L., Viscosity of lava, J. (jeol., f/, 27()-3(12, 1939.

Richter, D. H., and K. J. Murata, Xenolithic nodules in the $1800-1801$ Katupulehu flow of Hualalai volcano, Hawait, U.S. Geol. Sun: Proff. Palp., 424-B, B215-B217, 1961.

Schaber, G. G.. J. M. Boyce, and H. J. Moore, The searcity of mappable flow lobes on the lunar maria: Unique morphology of the Imbrium flows, Proc Lanar Sci. Conf., 7th, 2783-28010, 1976.

Stasiuk, M. V., C. Jaupart, and R. S. J. Sparks, On the variations of flow ratc in non-explosive lava cruptions, Earth Planet. Sci. Letl., $/ 1$, $505-516,1493$.

Stearns, H. T., The Keaiwa or 1823 lava tlow from Kilauca volcano. Hawaii, J. Gool, 34, 336-351, 1926.

Takahashi, T., Debris flow on prismatic open channel, J. Hydrarl Di: Am. Soc: (i1. Eng, J66(11Y3), 381-396, 1980.

Tazieff, H.. An exceptional cruption: Mt. Niragongo, Jan. loth. 1977. Bull. Volcand., 40(3), 189-20), 1977.

Wadge, G., The variations of magma discharge during basaltic eruptions, J. Volcanol Geotherm. Res., 11, 139-168, 1981.

Weir, G. J., Kinematic wave theory for Ruapehu lahars, New Zealand, J. Sci., 25, 197-2013, 1982.

Whitham, G. B., Linear and Nonlinear Waves, 637 pp., John Wiley, Now York, 1974.

Zimbelman, J. R., Estimates of rheologic properties for flows on the Martian volcano Ascraeus Mons, J. Geophys. Res., 90, 157D-162D, 1985.

S. Baloga (corresponding author), Proxeny Rescarch, 20528 Fareroft Lane, Laytonsville, MD 20882.

J. E. Guest, University of London Observatory, Mill Hill Road, London NW7 4SD, England.

P. D. Spudis, I.unar and Planetary Institute, 3600 Bay Area Blvd., Housion, TX 770158.

(Received May 15, 1995; revised September 7, 1995; accepted September 13, 1995.) 
